\title{
A Descentralização do Conhecimento para Melhoria dos Serviços em Gestão de Pessoas
}

The Decentralization of Knowledge to Improve Services in People Management

La descentralización del Conocimiento para el Mejoramiento de Servicios de Gestión de Personas

Paulo Rozendo da Paixão ${ }^{1}$

Patrícia de Cássia da Silva Bezerra ${ }^{2}$

\section{Resumo}

Objetivo: abordar o conhecimento acerca das atribuições dos diferentes setores que compõe a força de trabalho da Gestão de Pessoas de uma instituição pública de ensino superior. Método: realizar rodas de conversas, totalizando 3 encontros mensais, com duração de $2 \mathrm{~h}$ por dia, visando atender servidores, estagiários e jovens aprendizes, lotados no setor de Gestão de Pessoas. Resultados Esperados: oportunizar discussões acerca dos serviços disponibilizados, resgatar o sentido do trabalho, e (re) pensar os processos de trabalhos. Por fim, como produto final, será criado um blog que facilitará o acesso às informações relativas à gestão e o serviço. Conclusão: Espera-se que todas estas ações venham melhorar e modificar a realidade dos serviços executados na Gestão de Pessoas.

\section{Descritores: Administração de Recursos Humanos; Gestão do Conhecimento; Gestão em Saúde.}

\author{
Abstract \\ Objective: to approach the knowledge \\ about the attributions of the different
}


sectors that compose the work force in a Pro-Rectory of People Management. Method: to carry out conversational wheels, totaling in 3 monthly meetings, with average duration of $2 h$ per day. Aiming to serve servants, trainees and young apprentices, crowded in the People Management sector. Expected Results: provide opportunities for discussions about the services available, redeem the meaning of the work, and (re) think about the work processes. Finally, as a final product, a blog will be created to facilitate access to management and service information.

Conclusion: It is expected that all these actions will improve and modify the reality of the services performed in People Management.

\section{Descriptors: Personnel Management;} Knowledge Management; Health Management.

\section{Resumen}

Objetivo: Conocer el conocimiento sobre las funciones de los distintos sectores que componen la fuerza de trabajo en un Decano de Administración de Personal. Método: realizar ruedas de conversaciones, por un total de 3 reuniones mensuales, con un promedio de 2 horas por día. Para cumplir con los sirvientes, prácticas y los aprendices, de hacinamiento en el sector de gestión de personas. Resultados esperados: oportunizar discusiones acerca de los servicios prestados, para rescatar el sentido del trabajo, y (re) piensan que el proceso funciona. Por último, como producto final, un blog para facilitar el acceso a la información sobre la gestión y se creará el servicio. Conclusión: Se espera que todas estas acciones van a mejorar y modificar la realidad de los servicios prestados en Gestión de Personas.

Descriptores: Administración de Personal; Gestión del Conocimiento; Gestión en Salud.

\section{Introdução}

O Sistema Único de Saúde (SUS), criado no Brasil em 1988, com a promulgação da nova Constituição Federal, tornou o acesso gratuito à saúde direito de todo cidadão. Esse processo conformou-se em um espaço democrático de frequentes negociações desenvolvidas ao longo de diversas $\operatorname{etapas}^{(1)}$.

A implantação do SUS, baseado nos princípios da: Universalização do acesso às ações e serviços de saúde; 
Integralidade

da

atenção;

Descentralização com direção única do sistema e participação popular trouxe em sua premissa, a regionalização, a hierarquização, a descentralização, e a municipalização, uma vez que, antes de 1988, a saúde era responsabilidade de vários ministérios, deixando de ser exclusiva do Poder Executivo Federal e passando a ser administrada por Estados e Municípios $^{(2)}$.

$\mathrm{O}$ século $\mathrm{XX}$ foi um período de grandes transformações, em especial nas áreas: políticas, tecnológicas, econômicas e sociais, que fizeram com que as organizações e suas administrações modificassem sua maneira de atuar ${ }^{(3)}$.

Esse contexto aumentou significativamente $\mathrm{o}$ número de trabalhadores e de estabelecimentos de saúde pública e privada. O Brasil no final dos anos 70, contava com apenas 13.133 estabelecimentos de saúde, anos depois, em 1980, já se registravam 18.489, e em 2005, o número aumentou para 67.612 estabelecimentos de saúde. Essas transformações no cenário de trabalho tem exposto o trabalhador há uma série de desafios e tem exigido cada vez mais do setor de Recursos Humanos $^{(4)}$.

A área de Recursos Humanos (RH) no âmbito da saúde pública ganhou força a partir da década de 1970, quando se empoderou enquanto campo de estudos e pesquisas. $\mathrm{Na}$ década de 1980, os estudos já apontavam tendências macro do mercado de trabalho, tais como, o assalariamento, o aumento na carga horária de trabalho, o multiemprego, e a força da feminilização no trabalho. Em 1990, os estudos se voltaram para o mercado de trabalho, o mundo do trabalho, e a conformação das profissões da saúde ${ }^{(5)}$.

Considerando esse contexto dinâmico, o Ministério da Saúde em 2003, resolve criar a Secretaria de Gestão do Trabalho e da Educação na Saúde (SGTES), no intuito de fomentar, qualificar, valorizar e reconhecer o capital humano presente no SUS. Este fato possibilitou que à gestão de $\mathrm{RH}$, fosse considerada como um setor de nível estratégico. Neste sentido, os direcionamentos das ações priorizaram a dimensão do trabalho, e propiciou formular políticas voltadas para a gestão, formação, qualificação e regulação dos trabalhadores do SUS ${ }^{(6)}$.

Entende-se por gestão do trabalho, toda ação pensada e desenvolvida em prol dos trabalhadores, com a finalidade de melhorar os serviços oferecidos aos usuários do SUS, e tendo como premissa a fundamental participação 
desses atores no processo de elaboração e formação dos processos de trabalho ${ }^{(7)}$.

O cenário de saúde demanda que as organizações estejam preparadas para lidar com as incertezas inerentes a área, deve-se considerar estratégias que facilitem os processos de trabalhos e que tornem a rotina de trabalho mais flexíveis. É preciso criar estruturas organizacionais e formas de gestão que favoreçam a participação, a integração e a descentralização ${ }^{(8)}$.

Entre diversas ferramentas que a gestão do trabalho pode usufruir, utiliza-se para o enriquecimento desse estudo a gestão do conhecimento (GC). De acordo com Chiavenato ${ }^{(9)}$ a GC está destinada a integrar, criar, organizar e disseminar o conhecimento em todas as esferas da organização com o propósito de melhorar seu desempenho global.

Diante dessa complexidade que é fazer gestão do trabalho, este projeto de intervenção propõe, utilizar-se da ferramenta de GC para facilitar a disseminação do conhecimento acerca das atribuições dos diferentes setores que compõe a força de trabalho da Gestão de Pessoas de uma instituição pública de ensino superior na área de saúde no estado de Alagoas.

\section{Método}

O projeto de intervenção consiste na realização de rodas de conversas e possui um cunho qualitativo. Serão realizados um total de 3 encontros mensais, com duração média de $2 \mathrm{~h}$ por dia. O comparecimento dos participantes aos encontros dar-se-á por meio de presença espontânea, não podendo ultrapassar o total de 25 pessoas, tendo como quórum mínimo 13 pessoas. A cada encontro os setores terão 30min para se apresentar, 30min para construir um mapa estrutural sobre os principais serviços desenvolvidos, 30min para discussão dos processos de trabalho, e 30min destinado aos feedbacks dos participantes, com sugestões de mudanças, visando contribuir e agregar valor a cada setor que se apresentar. A proposta divide-se em três momentos, sendo esses: intervenção; composição dos resultados; e criação de um blog. Serão inclusos todos os servidores, estagiários e jovens aprendizes em exercício na Gestão de Pessoas. Serão excluídos os usuários dos serviços da gestão de pessoas.

A intervenção consiste na apresentação do autor e dos participantes; aplicação de técnica de sensibilização junto aos participantes do encontro para que possam aderir à proposta; apresentação da etiologia, epistemologia referente à $\mathrm{GC}$ e da 
proposta do projeto. Este momento será destinado a um rodizio de apresentações, onde um setor deverá apresentar o que sabe e conhece sobre o outro setor, e assim sucessivamente.

Em seguida, elaboração do mapa estrutural, discussão e feedback dos participantes quanto as apresentações. Os próximos encontros serão sistematizados e possibilitarão apresentações a respeito do papel, cargos e as atribuições de cada setor, estruturação de um mapa com os serviços desenvolvidos pelos setores, finalizando sempre com as discussões e feedbacks dos participantes, que promoverá sugestões de mudanças, resgate do sentido do trabalho, e (re)pensar os processos de trabalhos.

A segunda etapa consistirá na composição dos resultados de todos os encontros. Nesta fase serão aproveitados os registros elaborados (mapas estruturais) pelos grupos para que se possam documentar os conhecimentos apresentados ao longo dos encontros, e assim, transformar o conhecimento tácito em conhecimento explícito.

Por fim, a última etapa está destinada a criação de um blog, onde serão aproveitadas todas as documentações relativas aos conhecimentos registrados e expostos ao longo dos encontros pelos participantes. Esta fase se subdivide em: hospedar e registrar o domínio; parametrizar e configurar a base de dados; definir os requisitos funcionais, escolher e instalar o tema, em seguida postar todo conteúdo no blog e por fim, disponibilizar o mesmo na web.

A necessidade de realização da intervenção se baseou, em virtude de um concurso público para os cargos de nível médio e superior, em conformidade com os termos da Constituição Federal, da Lei Estadual $n^{\circ}$ 6.436/2003, da Lei Estadual $n^{\circ}$ $5.247 / 1991$.

A partir da chegada dos novos concursados, emergiu a necessidade de abordar junto a gestores, supervisores, estagiários, jovens aprendizes, e todo corpo administrativo da pró-reitoria o tema GC, no intuito de consolidar a integração das equipes, ampliar o conhecimento acerca dos diferentes setores da pró-reitoria, por meio de momentos de discussões sobre o "fazer" de seus próprios processos de trabalhos. 


\section{Quadro 1: Resumo do Plano de Intervenção}

\begin{tabular}{|c|c|c|c|c|}
\hline NÓ CRÍTICO & $\begin{array}{c}\text { OPERAÇÃO } \\
\text { (PROJETO/AÇÃO) }\end{array}$ & $\begin{array}{c}\text { CRONOGRAMA } \\
\text { EXECUÇÃO }\end{array}$ & $\begin{array}{c}\text { RECURSOS } \\
\text { NECESSÁRIOS }\end{array}$ & $\begin{array}{l}\text { RESULTADOS } \\
\text { ESPERADOS }\end{array}$ \\
\hline \multirow{4}{*}{$\begin{array}{l}\text { Desconhecimento } \\
\text { das atribuições } \\
\text { dos diversos } \\
\text { setores que } \\
\text { compõem a } \\
\text { PROGESP. }\end{array}$} & $\begin{array}{l}\text { Apresentação do } \\
\text { autor e dos } \\
\text { participantes } \\
\text { Aplicação de } \\
\text { técnica de } \\
\text { sensibilização } \\
\text { Apresentação do } \\
\text { conceito temático } \\
\text { "GC" }\end{array}$ & Novembro/2016 & Diálogo & \multirow{4}{*}{$\begin{array}{c}\text { Fortalecer a } \\
\text { gestão } \\
\text { participativa; } \\
\text { Proporcionar aos } \\
\text { trabalhadores da } \\
\text { PROGESP a } \\
\text { possibilidade de } \\
\text { discutir seus } \\
\text { processos de } \\
\text { trabalhos em um } \\
\text { ambiente coletivo; } \\
\text { Contribuir para a } \\
\text { disseminação do } \\
\text { conhecimento } \\
\text { acerca das } \\
\text { diferentes } \\
\text { atribuições que } \\
\text { compõem a força } \\
\text { de trabalho da } \\
\text { PROGESP, para } \\
\text { que se possa } \\
\text { melhorar e } \\
\text { modificar a } \\
\text { realidade do } \\
\text { serviço. }\end{array}$} \\
\hline & $\begin{array}{l}\text { Identificação de } \\
\text { quais são os } \\
\text { conhecimentos dos } \\
\text { novos concursados } \\
\text { sobre os diferentes } \\
\text { cargos e atribuições } \\
\text { dos setores que } \\
\text { compõe a } \\
\text { PROGESP. }\end{array}$ & $\begin{array}{l}\text { Novembro - } \\
\text { Janeiro/2016 }\end{array}$ & \multirow{3}{*}{$\begin{array}{l}\text { Papel A4 500 } \\
\text { fls; caneta } \\
\text { esferográfica; } \\
\text { lápis } n^{\circ} 08 ; \\
\text { borracha com } \\
\text { capa; e } \\
\text { apontador }\end{array}$} & \\
\hline & $\begin{array}{c}\text { Construção de } \\
\text { mapas estruturais }\end{array}$ & $\begin{array}{l}\text { Novembro - } \\
\text { Janeiro/2016 }\end{array}$ & & \\
\hline & $\begin{array}{c}\text { Identificações das } \\
\text { opiniões e } \\
\text { sugestões dos } \\
\text { participantes frente } \\
\text { aos setores expostos }\end{array}$ & $\begin{array}{l}\text { Novembro - } \\
\text { Janeiro/2016 }\end{array}$ & & \\
\hline $\begin{array}{l}\text { Dificuldade de } \\
\text { acesso às } \\
\text { informações } \\
\text { pertinentes aos } \\
\text { processos de } \\
\text { trabalho da } \\
\text { PROGESP }\end{array}$ & $\begin{array}{l}\text { Composição dos } \\
\text { resultados e criação } \\
\text { de um blog. }\end{array}$ & $\begin{array}{l}\text { Fevereiro - } \\
\text { Maio/2016 }\end{array}$ & $\begin{array}{c}\text { Ferramenta de } \\
\text { desenvolviment } \\
\text { o, hospedagem e } \\
\text { domínio de } \\
\text { blog: wordpress }\end{array}$ & $\begin{array}{l}\text { Espera-se que os } \\
\text { resultados dos } \\
\text { encontros } \\
\text { subsidiem a } \\
\text { criação de um } \\
\text { blog, objetivando } \\
\text { facilitar o acesso } \\
\text { ao conhecimento } \\
\text { de forma rápida e } \\
\text { fácil, tornando as } \\
\text { equipes das } \\
\text { supervisões mais } \\
\text { independentes e } \\
\text { eficientes na } \\
\text { eventual falta de } \\
\text { algum membro. }\end{array}$ \\
\hline
\end{tabular}




\section{Resultados Esperados}

Contribuir para elaboração de estratégias que facilitem a tomada de decisão dentro dos setores, e o processo de construção de políticas voltadas à própria gestão, com vistas a melhorar e modificar a realidade do serviço. Pretende-se ainda, fortalecer a gestão participativa; proporcionar aos trabalhadores a possibilidade de discutir seus processos de trabalhos em um ambiente coletivo; e contribuir para a disseminação do conhecimento acerca das diferentes atribuições que compõem a força de trabalho do órgão.

Por fim, que a intervenção fortaleça a comunicação interna, contribua na sistematização do fluxo dos processos de trabalho, que as intercorrências no acesso as informações e ao serviço, sejam sanados a partir dos encontros, materiais elaborados, e que a criação do blog facilite 0 acesso às informações relativas à gestão.

\section{Conclusão}

Espera-se que todas estas ações venham melhorar e modificar a realidade dos serviços executados na Gestão de Pessoas.

\section{Referências}

1. Conselho Nacional de Secretários de Saúde (BR). CONASS. Legislação Estruturante do SUS. Brasília: Conselho Nacional de Secretários de Saúde; 2011.

2. Sistema Único de Saúde (BR). SUS Democratiza o Acesso do Cidadão aos Serviços de Saúde. Portal Brasil. Brasília: Sistema Único de Saúde; 2009. [na internet]. [citado 2016 jul. 10]. Disponível em: http://www.brasil.gov. br/saude/2009/11/sus-democratiza-o-ace sso-do-cidadao-aos-servicos-de-saude.

3. Canuto RSL, Ribeiro CECG. O Papel do Setor de Gestão de Pessoas na Percepção das Demais Áreas de uma Unidade de Saúde de Maceió. (Alagoas) [periódico na Internet]. 2016 [citado 2016 jul. 15]; 1(1):18-26. Disponível em: http://www.seer.ufal.br/index.php/ nuspfamed/article/view/2378/1822.

4. Batista MRS, Macedo RA. PROGESUS. Ausência de Estrutura da Gestão do Trabalho e Educação na Saúde nos Municípios de Barra do Corda e Imperatriz de Maranhão. Recife: Fundação Oswaldo Cruz; 2009: 184-90. Disponível em: http://www.cpq am.fiocruz.br/bibpdf/2009batista-mrs. pdf.

5. Machado MH. Gestão do Trabalho Em Saúde. Dicionário da Educação Profissional em Saúde. Escola Politécnica de Saúde Joaquim Venâncio. Fundação Oswaldo Cruz. (Rio de Janeiro). [periódico na Internet]. 2009 [citado 2016 jun. 13]. Disponível em: http://www.sites.epsjv.fiocruz.br/ dicionario/verbetes/gestrasau.html. 
6. Mendonça MHM, Martins MIC, Giovanella L, Escorel S. Desafios para Gestão do Trabalho a partir de Experiências Exitosas de Expansão da Estratégia de Saúde da Família. (Rio de Janeiro) [periódico na internet]. 2010 [citado 2016 jul. 25]; 15(5): 2355-65. Disponível em: http://www6.ensp.fio cruz.br/repositorio/sites/default/files/arq uivos/DesafiosGest\%C3\%A3o.pdf.

7. Pierantoni CR, Varella TC, Santos MR, França T, Garcia AC. Gestão do Trabalho e da Educação em Saúde: Recursos Humanos em Duas Décadas do SUS. (Rio de Janeiro) [periódico na internet] 2008 [citado 2016 jul. 15]; 18(4):685-04. Disponível em: http:// www.scielo.br/pdf/physis/v18n4/v18n4 a05.pdf.

8. Castro JL, Vilar RLA, Liberalino FN. Gestão do Trabalho e da Educação na Saúde. (Natal). Rio Grande do Norte: UFRN; 2012.

9. Chiavenato I. Introdução à Teoria Geral da Administração: Uma Visão Abrangente da Moderna Administração das Organizações. Rio de Janeiro: Elsevier; 2003. 